\title{
Quando a sala de aula escuta e dança
}

\author{
Mônica Zewe Uriarte; Katia Franklin Baggio*
}

Resumo. Os temas "dançar conforme a música", "fazer a música para dançar" e "dançar sem música" pretendem despertar a curiosidade, desenvolver a autonomia e estimular as percepções de alunos e de professores envolvidos no cotidiano escolar. Dessa forma, trazemos para este estudo, inserido na temática de práticas educativas transformadoras e solidárias, algumas reflexões sobre a importância do professor na perspectiva da aprendizagem, como sujeito que preconiza atos em uma aula que podem, muitas vezes, ser considerados como obra de arte, dependendo da mediação por ele realizada na construção do conhecimento. Ressaltamos nesse estudo, as possibilidades de novas formas de olhar a escola por meio de uma Pedagogia escolar e social que conduza a práticas inclusivas e socializadoras. Nesse sentido, este texto avança a partir da metáfora do ouvir e dançar como práticas sensíveis, artísticas, estéticas e interdisciplinares, em um diálogo com Duarte Jr., Katrup, Meira, Rancière, Schafer e Uriarte sobre a educação emancipatória e autônoma dos envolvidos. Procuramos ressaltar a importância do aprender por meio de constante atualização na área específica e na conexão com a vida social e a natureza, compreendendo que o aprender das artes é tanto uma atividade cognitiva como cinestésica, e que não há aprendizagem sem inscrição corporal.

Palavras-chave: educação estética; práticas educativas transformadoras; emancipação; dança.

\section{CUANDO LA CLASE ESCUCHA Y BAILA}

Resumen. Los temas "bailar cómo la música", "hacer música para bailar" y "bailar sin música" pretenden despertar la curiosidad, desarrollar la autonomía y estimular las percepciones de alumnos y de profesores involucrados en la vida escolar. Así, traemos para este estudio, insertado en la temática de las practicas educacionales transformadoras y solidarias, algunas reflexiones sobre la importancia del profesor en la perspectiva del aprendizaje, cómo el sujeto que defensa actos en una clase que pueden, muchas veces, ser entendidos como obra de arte, dependiente de la mediación por él realizada en la construcción el conocimiento. Enfatizamos en este estudio las posibilidades de nuevas formas de mirar a la escuela por medio de una Pedagogía escolar y social que conduzca a prácticas inclusivas y socializadoras. En este sentido, este texto avanza a partir de una metáfora del oír y danzar como prácticas sensibles, artísticas, estéticas e interdisciplinares, en dialogo con Duarte Jr., Kastrup, Meira, Rancière, Schafer y Uriarte en la educación emancipadora y autónoma de los integrantes. Buscamos resaltar la importancia del aprender por medio

\footnotetext{
* Universidade do Vale do Itajaí (UNIVALI), Brasil.
} 
de una constante actualización en el área específico y en la conexión con la vida social y la naturaleza, comprendiendo que el aprender de las artes es una actividad no sólo cognitiva pero también cinestesica, y que no hay aprendizaje sin inscripción corporal.

Palabras-clave: educación estética; prácticas educativas transformadoras; emancipación; danza.

\section{WHEN THE CLASSROOM LISTEN AND DANCE}

Abstract. The themes "dancing according to the music, "making music to dance" and "dancing without music" aim to arouse curiosity, develop autonomy and stimulate the perceptions of students and teachers involved in everyday school life. Thus, we bring to this study, inserted in the theme of transformative and supportive educational practices, somereflections on the importance of the teacher in the perspective of learning, as a subject who advocates acts during a class that can often be considered as a work of art, depending on the mediation he performs in the construction of knowledge. We emphasize in this study the possibilities for new ways of looking at the school through a School and Social Pedagogy conducive to inclusive and socializing practices. In this sense, this text advances from the metaphor of listening and dancing as sensitive, artistic, aesthetic and interdisciplinary practices in a dialog with Duarte Jr., Kastrup, Meira, Rancière, Schafer and Uriarte on the emancipatory and autonomous education of those involved. We seek to emphasize the importance of learning through constant updating in the specific area and in the connection with social life and nature, understanding that the learning of arts is both a cognitive and kinesthetic activity, and that there is no learning without body registration. Keywords: aesthetic education; transformative educacional practices; emancipation; dance.

\section{INTRODUÇÃ̃o}

Vejo que nunca te disse como escuto música apoio de leve a mão na eletrola e a mão vibra espraiando ondas pelo corpo: assim ouço a eletricidade da vibração, substrato último do domínio da realidade, e o mundo treme nas minhas mãos.

(Lispector, 1998, p. 14)

Clarice Lispector (1998) escreve sobre a estesia que a música provoca no seu corpo, convidando-a a mover-se e perceber-se como ser único, que intui, sente e exala vibrações. Da mesma forma, pode-se dizer que o músico não toca a partir dos dedos ou canta apenas pela boca, e, também a música não se escuta somente pelas orelhas. Para fazer, sentir e ouvir música, o corpo é um todo solicitado para a escuta, para a execução e para o movimento. 
Se buscarmos um maior comprometimento nas relações inter e intrapessoais, poderemos alcançá-lo no trabalho de fortalecimento da formação de cada indivíduo e da educação como um todo. Nesse sentido, a arte apresenta-se como uma das possibilidades de efetivação desses anseios, neste texto, estudada especialmente a partir da música e da dança. Dependendo das propostas de aproximação e maior envolvimento com essas áreas, as práticas artísticas apresentam-se como opções privilegiadas "[...] para o exercício de qualidades transversais a toda educação, como a cooperação, a paciência, a gentileza, a relativização da competição, a escuta de si e do outro" (Molina, 2012, p. 7). Apesar da consciência de que essas qualidades devem permear todos os campos do saber e da convivência, nas artes elas se apresentam como "[...] pré-requisitos, engrenagens, encaixes para um movimento conjunto, propiciando o fluir da criatividade, e pode trabalhar sem grandes obstáculos, o exercício da liberdade com responsabilidade" (Molina, 2012, p. 8).

Novas formas de olhar a escola, pressupõe a superação do sentido restrito e tradicional das práticas escolares, assim, por meio de uma Pedagogia Escolar e Social que conduza a práticas inclusivas e socializadoras se pode contribuir para a transformação das pessoas. Diante da impossibilidade da escola de responder aos diversos desafios do tempo tecnológico, caminhos que conduzam à educação permanente colaboram na superação das restrições educativas e conduzem a práticas e teorias transformadoras promovidas pela Pedagogia Social e com ela uma Educação Social.

Os movimentos anteriormente citados podem potencializar uma educação estética como uma possibilidade de enriquecer e proporcionar vias alternativas de construções de conhecimentos. A sala de aula que escuta e dança pode proporcionar novas formas para encontrar outros caminhos. "[...] hoje, em tempos de muitas transformações, a estética procura seus contornos" (Martins, 2011, p. 312). Assim sendo, partimos do pressuposto de que a arte provoca diálogos internos, por meio do acesso a uma determinada forma ou objeto, em que o descobrir e o conhecer favorecerão encontros sensíveis, podendo alcançar outros pontos de vista ou novas significações.

\section{PREPARANDO A SALA}

Trazemos para este estudo algumas reflexões sobre a importância do professor na perspectiva da aprendizagem, como sujeito que preconiza atos em uma aula que podem, muitas vezes, ser considerados como obra de arte, dependendo da mediação por ele realizada na construção do conhecimento. Esse professor mediador, emancipador, promove o encontro, enquanto o 
mestre explicador não avança no sentido de propiciar experiência, gerando dependência. Para Rancière (2013), o emancipador tem uma ação de mediar, enquanto ao explicador cabe a função de apresentar.

Nesse sentido, este texto avança a partir da metáfora do ouvir e do dançar, como práticas sensíveis, artísticas, estéticas e interdisciplinares, bem como argumenta que a educação que se constitui a partir dessas características concorre para a emancipação dos sujeitos envolvidos, aos quais é dada a possibilidade de manifestarem-se de forma autônoma. Assim essa concepção ressalta os conceitos atuais de uma Educação Social em possibilitar formas complementares de uma educação permanente das pessoas.

Procuramos ressaltar a importância do aprender com o aprender, pois é imprescindível para o professor manter-se atualizado na área de conhecimento em que atua, conectado à vida social e à natureza inacabada do saber. 0 aprender das artes é tanto uma atividade cognitiva como cinestésica, pois não há aprendizagem sem inscrição corporal que de algum modo promove experiências pela visão, olfato, tato, movimento, audição, e outras percepções que decorram do deixar-se afetar. "A música não se manifesta apenas pelas mãos ou pela voz, porque ela envolve todo o corpo, desde a cognição, a atenção, a preparação física e emocional, para então poder transbordar em sonoridades" (Uriarte, 2015, p. 28). Com isso, a inquietação com os modos de ensinar resultou neste texto, que propõe como possibilidades os temas "dançando conforme a música"; "fazendo a música para dançar" e "dançando sem música".

\section{DANÇANDO CONFORME A MÚSICA}

É necessária uma contaminação estética para que os processos de mediação cultural se efetivem. Para Martins (2014), essa contaminação acontece por meio de recursos humanos e recursos culturais. Os recursos humanos voltam-se aos sujeitos que assumem o importante papel de instigadores, promovendo a difusão e a contaminação estética. Os recursos culturais estão voltados ao sujeito, seu lugar e suas referências, que serão partilhados e ampliados por meio da mediação cultural.

Esse movimento de contaminação estética busca promover encontros significativos com a arte em suas diferentes manifestações, nesse caso, especialmente com a música e a dança - o que é mediado pelo professor emancipador "[...] que provoca nossos sentidos, convoca a cognição e instiga percepções individuais" (Uriarte, 2017, p. 87). Destacamos, no entanto, que ser professor não faz desse profissional um mediador, porque o que caracteriza 
um mediador são suas ações com ênfase nos encontros que ele propõe com a arte e a cultura, gerando as contaminações estéticas, que irão capturar o grupo para a dança e a música.

Usamos a palavra "Estética" no sentido dado pelo Grego Aisthésis, como a faculdade de sentir. No entanto, para Duarte Jr. (2012, p. 23), "[...] este sentir o mundo não é meramente sensação. No ato de sentirmos o mundo já damos um sentido para ele, nós já damos um significado para ele". O mesmo autor salienta que a valorização da educação da sensibilidade, oportuniza ao ser humano "[...] a capacidade de sentir a si próprio e ao mundo num todo integrado" (Duarte Jr., 2001, p. 13).

Ao pensar na valorização da sensibilidade, usamos a metáfora "dançando conforme a música" considerando que a educação visa desenvolver sujeitos autônomos e criativos, e não sujeitos que se repetem sem questionamentos. Para fazer uma sala de aula ouvir e dançar, o processo precisa ser flexível e aberto, de forma a possibilitar o máximo de liberdade e opções de decisão pessoal dos participantes, além de um conhecimento prévio do que se pretende realizar. Isso não dispensa um direcionamento claro e definido no que diz respeito aos objetivos, que devem voltar-se para a escolha ou a criação de uma obra artística, estética e sensível que tenha significado para os participantes, o que somente será possível quando o processo for iniciado pela escuta consciente e atenta do grupo.

No trabalho do professor que propõe a dança, há uma tendência em pretender a perfeição de cada um dos movimentos, o que é impossível nos primeiros tempos. Além disso, a repetição exaustiva de um movimento corporal único e, sempre perseguindo um compasso da música imposta para dançar, faz com que se perca a visão de conjunto, podendo resultar em movimentos diluídos e vazios, ou, muitas vezes, repetitivos, sem demonstrar a necessária articulação com a música que deveria ser o seu estímulo.

Outra tendência que pode acelerar o processo é a pressa de ensinar em pouco tempo de estudos, o que o professor adquiriu, com esforço, ao longo de sua carreira. Com esses percalços, o processo de assimilação desvia-se saltando etapas imprescindíveis na formação de seus alunos, com a agravante de que os novos conhecimentos e sensações terão perdido seu frescor e interesse, principalmente se forem submetidos a acompanhar uma música pré-determinada, sem a clareza de o porquê e com qual intenção.

O que se deve buscar na aliança entre música e dança é o equilíbrio da proporção entre conteúdo e forma. Nenhum movimento deve ser vazio, mas sim realizado, muitas vezes, no transcurso do processo de aprendizagem. Assim, em cada oportunidade, ele deve ser executado como fato único, 
recém-descoberto e novo. 0 conteúdo do movimento não deve alterar a forma, mas deve contribuir na expressividade. Nesse sentido, ouvir a música com atenção é parte imprescindível no processo criativo. 0 que propomos é que a dança da sala de aula deve possibilitar acesso ao terreno da investigação, da afetividade, da percepção artística e da crítica, pois só assim essa prática se constituirá em momento não apenas de estesia, mas também de autonomia.

Paulo Freire (2004) fala-nos sobre a necessidade de os educadores criarem condições para que o conhecimento seja construído pelos alunos, como um processo no qual estes não se reduzam a objetos uns dos outros "[...] ensinar não é transferir conhecimento, mas criar as possibilidades para a sua própria produção ou a sua construção" (Freire, 2004, p. 47). Para que esse processo se constitua de forma a gerar autonomia, é importante que o professor possua autocrítica, que se coloque em constante esforço de aperfeiçoamento e esteja aberto às indagações e às perguntas dos alunos. Desse modo, as práticas educativas transformadoras e solidárias abrem caminhos para a superação do sentido restrito da educação tradicional, transformando essas práticas e teorias em processos inclusivos, solidários e transformadores no convívio social.

0 professor emancipador e mediador apresentado por Rancière 116 (2013), traz dentro de si a inquietude, a curiosidade do artista, e por isso promove contatos com a arte e a cultura. Esse professor que opta pela emancipação intelectual pretende comprovar que as inteligências são iguais: "Não há ignorante que não saiba muitas coisas que tenha aprendido sozinho, aguçando os sentidos para ver e ouvir o que acontece à sua volta, observando, fazendo e repetindo até aprender" (Uriarte, 2017, p. 86). Já o professor explicador (Rancière, 2013) ensinará uma dança com movimentos vazios e repetitivos, que acabará por gerar o embrutecimento. Assim, ao "dançar conforme a música", o professor pode não passar de um repetidor de movimentos sem expressão, sem acrescentar nada de novo, nem ao contexto, nem ao aluno.

Diante desse pressuposto, o papel do professor pode ser transformado, pois educar para autonomia, preparando pessoas para as demandas contemporâneas, recorre à figura do professor como mediador de seus conhecimentos, que, até então, dançava conforme a música. 0 professor passa, desse modo, a repensar sua prática e teorias, como elementos ativos de um processo. Quando as sugestões e as proposições são trabalhadas como forma de extensão do conhecimento, em uma ação mediadora, busca-se interpretar as novas informações, direcionando-se aos objetivos previamente definidos, ou, ainda, aos que poderão ser propostos. 
Professores e estudantes em uma sala de aula devem questionar e permitirem ser questionados. A atitude de questionar provoca a desacomodação do ambiente, devido à predominância do diálogo crítico que caracteriza a educação emancipadora para que o novo possa emergir. 0 professor consciente de que a prática artística promove sensações e percepções pode catalisar a aprendizagem com energia permanente, provocado pelo diálogo crítico, desenvolvendo, assim, a autonomia na construção de argumentos. O desequilíbrio natural do diálogo deve ser percebido pelo professor e encaminhado para a superação da retransmissão de cânones que Ihe foram ensinados para promover a provocação, e dessa forma, o novo possa emergir.

Diante desses argumentos, podemos supor que o professor que possibilita a intervenção dos alunos na proposição da coreografia de sua aula está rompendo com o que se costumava fazer até então. Ele promove as pessoas envolvidas para um primeiro plano e proporciona o exercício da capacidade de ouvir o que os alunos têm a expressar, e incentiva os colegas por emulação a respeitar a fala dos outros, considerando cada argumento como possibilidade para a construção de outros mais consistentes. Em paralelo, permite que o professor faça leituras de novas linguagens e simbologias usadas pelos alunos, resultado de suas experiências e aprendizagens.

Desse processo é que surgirá a coreografia da dança, uma dança coerente com as possibilidades do grupo, que passará a agir conforme nos indica Ligia Clark (1980, p. 31): "Nós somos os propositores: nós somos o molde, cabe a você soprar dentro dele o sentido da nossa existência". Por isso é que o professor atento aprende a ouvir o que dizem os alunos e instigaos a pensar, a refletir, a interpretar e a reelaborar, evidenciando autonomia, tanto quanto um dançarino precisa ouvir o ritmo da música se quiser estar em consonância com ela.

\section{FAZENDO A MÚSICA PARA DANÇAR}

Usamos mais essa metáfora na busca de compreender de que modo nos movimentamos quando pretendemos aprender algo, ou quando pretendemos promover a aprendizagem. Fazer a própria música para dançar implica estar impregnado do que se quer criar em termos de movimento para essa dança, ou seja, ter uma intencionalidade. Esse movimento que se busca, possui uma estreita relação com as possibilidades de cada aluno de se transformar em um sujeito autônomo, socialmente responsável, criativo e crítico. Autonomia carregada de dimensões estéticas e humanizadoras, carregada de cuidados, de sensibilidades, de ternuras, de finos tratos, de 
musicalidade, de ritmo nos atos de ensinar e de aprender. "As artes nos têm mostrado com expressões diversas que há uma poética e uma estética no magistério" (Arroyo, 2008, p. 126).

As artes têm uma grande importância como um empreendimento intelectual, cognitivo, pois envolve a descoberta e a resolução de problemas. 0 questionar aplica-se a tudo que constitui o ser. 0 professor que motiva seus alunos para que descubram caminhos em busca de soluções estará exercitando essa competência. Isso exige uma nova postura do professor, que envolve seu discurso carregado de crenças e ações que pensem um novo fluxo de aprendizagem. Esse fluxo promove o desenvolvimento de habilidades para refletir, detectar fragilidades e potenciais, tanto na sua conduta como na dos alunos. Um meio para emergir dessa situação parte da observação de procedimentos adotados e da procura por uma intencionalidade que atenda às necessidades do grupo.

Afirmar que as coisas são difíceis para o professor é redundante. Consideramos ser o professor o mais apto para o uso das linguagens estéticas, metáforas, música, dos sentimentos e da emoção para transformar a sua prática e, por consequência, as relações de ensino e de aprendizagem. 0 propósito de incentivar a emancipação e a autonomia intelectual do aluno é percebido pelo professor, quando este possui a autonomia intelectual, criando, assim, oportunidades para que os alunos desenvolvam as habilidades de refletir e de resolver problemas.

A conduta do professor como criador de condições, na sala de aula, para a promoção da autonomia, é aqui definida como mediadora. Ao refletir a respeito da consistência do discurso que adota, guiará os alunos a aprender a aprender. Trata-se de ampliar o conceito de aprender baseado nos sentimentos e na cognição das pessoas, preconizando o desenvolvimento do intelecto.

Assim, toda dança bem como a pesquisa artística começam no ser, quando este se questiona, levado pela ação intencional do professor que promove um movimento no sentido de elaboração própria. 0 professor que tem habilidade para utilizar tais pressupostos prepara com cuidado as ideias, diferenciando a sua aula e promovendo a melhoria do desempenho no trabalho, o que pressupõe um conhecimento sólido a respeito do que pretende ensinar. 0 professor precisa usar seu conhecimento aprofundado, julgar sua pertinência em relação a uma determinada situação e mobilizá-lo com discernimento, desempenhando, assim, seu trabalho com mais comprometimento e possivelmente com mais segurança. 
Em contato com diversas vivências artísticas, os professores podem ter novas experiências e, por meio delas, sensibilizar-se e refletir sobre sua atuação no meio escolar. "A apreciação artística, portanto, leva o sujeito a perceber-se no contexto em que está inserido, podendo esse movimento levá-lo a enxergar também o outro, num processo de autoconhecimento que 0 auxiliará a desenvolver seus sentidos e ampliar significados" (Neitzel; Carvalho, 2013, p. 1024). Ampliar os significados permite novos olhares para a escola e proporciona novas possibilidades de práticas inclusivas, solidárias e positivamente transformadoras do convívio social.

Nesse contexto, o professor procura fazer a própria música para dançar, possibilitando que seus alunos criem coreografias a partir de suas motivações. Tais como a música e a dança representam um contexto cultural, o professor tende a despertar os interesses de seus alunos, estabelecendo relações que podem gerar novo conhecimento. Em uma cultura cada vez mais diversificada e em um horizonte permeado de contradições, a "criatividade" é uma palavra-chave que pressupõe uma nova postura para o ser humano perante a vida, voltada para perceber, sentir e viver a realidade. Considerando as novas linguagens, a mídia propicia modos inusitados de percepção das realidades, muitas vezes modificando seu significado e, sensivelmente, seu meio cultural.

\section{DANÇANDO SEM MÚSICA}

O propósito dessa metáfora é no sentido de que podemos nos movimentar em uma dança mesmo sem a presença de sons, pressupondo que o silêncio muitas vezes pode ser um norteador para os movimentos.

"O silêncio não existe. Sempre está acontecendo alguma coisa que produz som" diz-nos Schafer (1991, p. 130), indicando que, no mundo atual, o silêncio absoluto não é mais possível. Desse modo, sempre teremos alguma interferência sonora, seja ela musical, ruidosa, programada ou ocasional. Isso significa que os movimentos poderão sempre buscar acompanhamento de diferentes sonoridades que estão dispostas no mundo que habitamos. Schafer (1991, p. 149) acrescenta que "não temos pálpebras auditivas", o que significa que a audição é o sentido do qual não podemos nos isolar, pois as sonoridades, mesmo que internas do nosso corpo, estarão sempre presentes no movimento.

É componente fundamental da dança na sala de aula aprender a perceber. Para que uma dança seja executada sem a influência de música, o executor dos movimentos pode ainda contar com sua intencionalidade e com 
a produção de sons internos que o levem a seguir um ritmo próprio e individual, não menos importante e eficiente. 0 desenvolvimento do pensamento criativo deveria ser um objetivo prioritário ao pensarmos em educação sensível.

[...] educação como um processo formativo do humano, como um processo pelo qual se auxilia o homem a desenvolver sentidos e significados que orientem a sua ação no mundo. Neste sentido, o termo educação transcende os limites dos muros da escola, para se inserir no próprio contexto cultural onde se está. (Duarte Jr., 1981, p. 15).

A experiência sensível em sala de aula propicia um envolvimento ativo e reflexivo permanente de seus participantes. Um professor emancipador é fundamental para pôr em movimento todo um conjunto de ações e de argumentações que possibilitem superar o estado atual e atingir novos patamares do ser, do fazer e do conhecer.

A qualidade do trabalho do professor depende das experiências que este compartilha com seu aluno e do diálogo com níveis sempre crescentes que o estudante venha a promover, seja movido por curiosidade, dúvida ou questionamentos sobre a realidade compartilhada por ambos, mesmo que, por vezes, incomodados pelo comprometimento da realidade social.

Um professor que faz a sala de aula dançar conhece a expressão do rosto do aluno, mesmo que este se encontre de costas, pois o rosto é apenas uma síntese expressiva do estado de ânimo que o dançarino traduz em todos os músculos de seu corpo. "Tratar o sentido de aprender pelos sentidos depende de afinar o corpo para vibrar de modo qualitativo em relação aos eventos sociais, mas especialmente aos que caracterizam o fazer artístico" (Meira, 2014, p. 53). Destarte, professores capazes de agir criticamente na sociedade em que estiverem inseridos ensinam o conteúdo formal de sua disciplina e se mantêm atentos ao contexto social de seus alunos.

O professor que tem por hábito fazer sua própria música certamente desacomoda o ambiente propositivo, desencadeando novas propostas coreográficas que serão percebidas pelos alunos. Cabe ao professor validar essas propostas por meio da discussão de ideias e de desenvolver a capacidade de respeitar o argumento do outro. Promover o reinício do processo, questionando, estando aberto para superar-se e ser superado, em um movimento de construção permanente. Dessa forma, é possível criar um ambiente de liberdade, de respeito, de escuta e de diálogo, que são condições essenciais para a autonomia que decorre das trocas de informação pelos pares. 
Um professor comprometido e competente no seu trabalho possibilita a geração de novos conhecimentos capazes de promover benefícios para uma comunidade específica, aproximando as pessoas não só do processo de produção de novas ideias como também de decisões sobre sua utilização. Kastrup (2007, p. 174) afirma: "O melhor aprendiz não é aquele que aborda o mundo por meio de hábitos cristalizados, mas o que consegue permanecer sempre em processo de aprendizagem".

A dança que é criada e trabalhada em equipe promove a flexibilidade necessária para encaminhar a busca de soluções satisfatórias dos problemas coreográficos, de unir o movimento individual com o coletivo, construindo, por conseguinte, uma obra coreográfica com argumentações mais consistentes. 0 envolvimento permite aos participantes um melhor conhecimento de si mesmos e do mundo, estabelecendo relações significativas entre os novos conhecimentos e os já adquiridos. Nesse processo, o professor precisa dar sua contribuição pessoal, propondo novas experiências. Essa marca pessoal caracteriza um sujeito capaz de elaboração própria, como um dos primeiros passos em uma dança silenciosa, pois novas alternativas na construção de uma aprendizagem significativa podem delinear perspectivas de ação nessa dança que promove avanços na construção de conhecimentos cognitivos, sensíveis e afetivos.

\section{CONSIDERAÇÕES FINAIS}

"Dançar conforme a música", "fazer a música para dançar" e "dançar sem música" são movimentos que despertam a curiosidade, desenvolvem a autonomia e estimulam as percepções. É papel do professor mediador, que anda junto, promover esses movimentos de arte e cultura, com o objetivo de estesiar os seus sentidos assim como do seu grupo, na busca pela qualidade da educação.

Caminhos como a Pedagogia escolar e social conduzem a superação dos sentidos restritos da educação convencional, contando com novas formas de olhar a escola e as práticas educativas, tornando-as inclusivas, transformadoras e solidárias. Uma das contribuições da Pedagogia escolar e social é a possibilidade de compreender os desafios dessa era tecnológica, pelo reconhecimento de que práticas e teorias que promovam a autonomia das pessoas também podem proporcionar uma educação permanente e transformadora, em prol de uma sociedade mais apta e sensível às rápidas transformações. 
Quando essas propostas são ofertadas, a escola transforma-se em um lugar mais atraente para os alunos, pois fornece-lhes possibilidades de compreender a vida em sociedade de forma mais participativa. É a qualidade e a motivação dos professores que pode mobilizar experiências mais sensíveis, desvelando o ritmo pessoal de cada um no caminho pela construção de um movimento autônomo, ativo e reflexivo, iniciado na dança, mas que poderá ser transposto para as ações cotidianas, assim como para as diversificadas situações do cotidiano escolar.

Na educação, percebe-se necessário que estejam mais presentes o diálogo e a afetividade, colocando em constante relação o sensível e o inteligível, o que poderá ser observado a partir do ato pedagógico que envolva uma intensa relação cognitiva e afetiva entre os participantes do processo ensino-aprendizagem.

Com isso, o "dançando conforme a música", "fazendo a música para dançar" e o "dançando sem música" sugerem possibilidades de potencializar uma Educação Estética que promova a emancipação dos envolvidos, podendo desencadear diversificadas propostas educativas que possibilitem mais expressividade.

\section{REFERÊNCIAS}

Arroyo, M. G. (2008). Uma Celebração da Colheita. In: Teixeira, I. A. de C; Lopes, J. S. M. A escola vai ao cinema. Belo Horizonte: Autêntica.

Clark, L. (1980). Textos de Lygia Clark, Ferreira Gullar e Mário Pedrosa. Rio de Janeiro: Funarte.

Duarte Jr., J. F. (1981). Fundamentos estéticos da Educação. São Paulo: Cortez.

Duarte Jr., J. F. (2001). O sentido dos sentidos: A educação (dos) sentidos. Curitiba: Criar Edições.

Duarte Jr., J. F. (2012). Por que Arte-Educação?. Campinas: Papirus.

Freire, P. (2004). Pedagogia da autonomia: Saberes necessários à prática educativa. São Paulo: Paz e Terra.

Katrup, V. (2007). A invenção de si e do mundo. Uma introdução do tempo e do coletivo no estudo da cognição. Belo Horizonte: Autêntica.

Lispector, C. (1998). Água viva. Rio de Janeiro: Rocco.

Martins, M. C. F. D. (2011). Arte, só na aula de arte? Educação 34(3), set./dez, Porto Alegre.

Martins, M. C. F. D. (2014). Mediações culturais e contaminações estéticas. Revista Gearte, 1(2), pp. 248-264, ago. Porto Alegre. 
Meira, M. O. , 2014. Sentido de aprender pelos sentidos. In: Pillotto, S. S. D.; Bhon, L. R. D. Arte/Educação: Ensinar e aprender no Ensino Básico, pp. 53-62. Joinville: Univille,

Molina S. (2012), Vozes e Ouvidos para a música na escola. In: Jordão, G.; Allucci, R. R.; Molina, S. (Orgs.). A música na escola, pp. 7-10. São Paulo: Allucci \& Associados Comunicações.

Neitzel, A. de A.; Carvalho, C. (2013). A estética na formação de professores. Revista Diálogo Educacional 13(40), set./out, Curitiba.

Rancière, J. (2013). O mestre ignorante: cinco lições sobre a emancipação intelectual. Tradução Lioian do Valle. Belo Horizonte: Autêntica.

Schafer, M. (1991). O ouvido pensante. Tradução Marisa Trench de O. Fonterrada. São Paulo: UNESP.

Uriarte, M. Z. (2015). Voz, memórias e outras sonoridades do PIBID de Música. Joinville: Univille; Itajaí: Univali.

Uriarte, M. Z. (2017). Escola, música e medicação cultural. Curitiba: Appris. 
